\title{
JOURNAL ON EDUCATION IN EMERGENCIES
}

Mindful Learning: Early Childhood Care and Development for Refugee Children in Tanzania

Author(s): Kelsey A. Dalrymple

Source: Journal on Education in Emergencies, Vol. 5, No. 1 (December 2019), pp. 133-155

Published by: Inter-agency Network for Education in Emergencies

Stable URL: http://hdl.handle.net/2451/60977

DOI: https://doi.org/10.33682/37cx-3017

\section{REFERENCES:}

This is an open-source publication. Distribution is free of charge. All credit must be given to authors as follows:

Dalrymple, Kelsey A. 2019. "Mindful Learning: Early Childhood Care and Development for Refugee Children in Tanzania." Journal on Education in Emergencies 5 (1): 133-55. https://doi.org/10.33682/37cx-3017.

The Journal on Education in Emergencies (JEIE) publishes groundbreaking and outstanding scholarly and practitioner work on education in emergencies (EiE), defined broadly as quality learning opportunities for all ages in situations of crisis, including early childhood development, primary, secondary, non-formal, technical, vocation, higher and adult education.

Copyright (C) 2019, Inter-agency Network for Education in Emergencies.

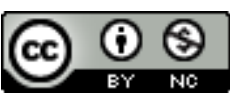

The Journal on Education in Emergencies, published by the Inter-agency Network for Education in Emergencies (INEE), is licensed under a Creative Commons Attribution-NonCommercial 4.0 International License, except where otherwise noted. 


\title{
MINDFUL LEARNING: EARLY \\ CHILDHOOD CARE AND DEVELOPMENT FOR REFUGEE CHILDREN IN TANZANIA
}

\author{
Kelsey A. DAlRymple
}

\begin{abstract}
This field note presents findings from an assessment conducted on the Little Ripples program, which was piloted with Burundian refugee children ages three to five in Tanzania. The aim of the assessment was to understand the general progress of the program, attitudes and perceptions about the use of mindfulness in the classroom, and the perceived effects on students and teachers who participated in the pilot. This field note provides an overview of the Little Ripples program approach; the gaps the program is aiming to address in emergency early childhood care and development services; the concept of mindfulness and its use as a teaching tool; the Little Ripples program assessment methodology and results; and recommendations for ways forward.
\end{abstract}

\section{THE IMPORTANCE OF EARLY CHILDHOOD}

The earliest years of life are a critical time for individual growth and development. Experiences during this period can have a long-lasting effect on a child's future. Consequently, early childhood experiences can impact the future economic and social prosperity, productivity, and sustainability of entire communities and societies (Gertler et al. 2014; World Health Organization et al. 2018). Multidisciplinary research conducted over the last few decades shows that, by the time a baby is born, the brain contains almost all the neurons it will ever have, and that, by age two, a massive number of neuronal connections are made in response to interactions with caregivers and environments (World Bank Group, United Nations Children's Fund, and Inter-American Development Bank 2018).

Received October 16, 2018; revised August 1, 2019; accepted September 3, 2019; electronically published December 2019.

Journal on Education in Emergencies, Vol. 5, No. 1

Copyright (C) 2019 by the Inter-agency Network for Education in Emergencies (INEE).

ISSN 2518-6833 
In keeping with these findings that brain development is influenced by early life experiences and surroundings, research has established that nurturing care in particular areas, including health, nutrition, early learning, responsive caregiving, and safety and security, can help children become healthier, more productive, and more successful members of society (World Bank Group et al. 2018). Conversely, children who do not receive this essential care, or who experience intense stress or trauma such as extreme poverty, violence, displacement, or nutritional deprivation during their early years, can suffer from poor brain development, which can have developmental consequences well into adulthood.

An estimated 250 million children under age five in low- and middle-income countries are at risk of not reaching their developmental potential due to inadequate nurturing care (Black et al. 2016), and an estimated 87 million children under age seven have spent their entire lives in conflict zones (Inter-agency Network for Education in Emergencies [INEE] 2017). Poverty, conflict, and humanitarian crises often exacerbate already difficult conditions, weaken normal support systems, and make children more vulnerable to harm or neglect. In emergency situations, children often are separated from their parents and caregivers, may lose their sense of stability and comfort, and are at risk of not having their basic needs met.

Early childhood care and development (ECCD) in emergencies is commonly defined as providing immediate, life-saving, comprehensive care for children from conception to age eight (Plan International 2013). Humanitarian approaches to providing ECCD in emergencies are often rooted in the Nurturing Care Framework (World Health Organization, United Nations Children's Fund, and World Bank Group 2018). These programs aim to provide essential multi-sectoral support for children in the areas of early learning and stimulation, health and nutrition, and safety and security through organized academic and recreational activities in safe spaces, while also encouraging parents and caregivers to engage and interact regularly with their children at home.

Nevertheless, there is a critical gap in ECCD in emergencies programs. Simply providing access to basic early learning activities during emergencies is not enough; these activities must be safe, fun, and engaging, as this is key to helping children develop important social-emotional skills for lifelong learning and healthy psychosocial well-being (Bouchane, Curtiss, and Ellis 2016; UNICEF 2012; Bouchane et al. 2018). Few ECCD in emergencies programs-at least few that have been documented-incorporate non-traditional social-emotional teaching techniques such as mindfulness, which promote executive functioning and selfregulation skills and can help create peaceful classrooms and communities, which 
is incredibly important for refugee communities that have experienced extreme violence and trauma. The following pages describe Little Ripples, a program that aims to address this gap.

\section{LITTLE RIPPLES: A MINDFUL APPROACH}

Little Ripples is an innovative early childhood education program that trains refugee men and women to support the comprehensive needs of refugee children ages three to five. The program was developed and piloted in 2013 with Darfuri refugees living in the Goz Amer camp in eastern Chad. Initially, 14 refugee mothers and female caregivers were trained and employed to support 250 refugee children. The program has since expanded into four refugee camps in eastern Chad, where it has trained 97 Darfuri refugee teachers and reached 3,000 Darfuri refugee children. The program has also been adapted and implemented with refugees from the Central African Republic in Cameroon and Burundian refugees in Tanzania, where it has trained 92 teachers and reached more than 7,000 children. The program intends to continue to expand to serve additional communities affected by humanitarian crises.

Little Ripples uses an evidence-based (Harvard University Center on the Developing Child 2018) early childhood education framework developed by $\mathrm{iACT}$, a U.S. humanitarian non-governmental organization (NGO) that focuses on early learning, leadership, and sports initiatives for refugee communities. The Little Ripples curriculum was developed in consultation with experts in early childhood development, education, trauma recovery, and mindfulness, and is designed for use in various contexts, including refugee and non-refugee situations. The curriculum also trains early childhood teachers with any level of education and experience to use positive behavior management techniques to deliver play-based learning activities that foster social-emotional development. ${ }^{1}$ The curriculum is designed to be used with any existing academic or pre-primary curricula by trained teachers, parents, or caregivers, and it can be adapted as needed. Those trained to deliver the curriculum are encouraged to do so using activities, stories, music, and games that are unique and relevant to their respective cultures, languages, and contexts.

1 Sometimes referred to as positive discipline. 
A key aspect of the Little Ripples curriculum is the incorporation of mindfulness. Mindfulness is a type of awareness that is cultivated by paying attention to the present moment in a way that is open, curious, and non-judgmental; it teaches individuals how to regulate their attention and energy by encouraging them to focus on the present moment (Foundation for a Mindful Society 2017; Kaiser Greenland 2010; Kabat-Zin 2003). Young refugee children face numerous challenges that can negatively affect their psychosocial well-being and ability to learn. Incorporating mindfulness into the Little Ripples curriculum helps these young learners find stability and comfort in the chaos of displacement, nurtures their internal peace so they can become resilient, helps them develop executive functioning and self-regulation skills, and teaches them mindfulness practices they can carry with them as they transition into adolescence and adulthood.

In a Little Ripples classroom, mindfulness is not practiced as a stand-alone activity. Teachers are encouraged to incorporate mindfulness activities throughout their lessons to help promote positive learning outcomes, as well as individual growth and development. Teachers guide their students in practicing mindfulness exercises in daily "welcome" and "goodbye" circles. They also lead mindful moments throughout the day if they feel their students would benefit from a calming exercise. On any given day in a Little Ripples classroom, you might see children sitting with their hands on their stomach as they feel it rise and fall with their breath, lying down as they do a mental body scan, or swaying slowly back and forth to the soft sound of a drum.

\section{MINDFULNESS AND EARLY LEARNING}

In the last two decades, there has been immense interest in and research on social and emotional learning (SEL), particularly in an education context (Byrd 2019; Jones and Bouffard 2012; Weissberg 2019; Zins and Elias 2006). SEL programs are currently used in thousands of schools and learning spaces around the world. They often are based on the Collaborative for Academic, Social, and Emotional Learning (CASEL) framework, which promotes the development of competencies in self-awareness, self-management, social awareness, relationship skills, and responsible decision-making (CASEL 2018).

Much of the current discussion on SEL is focused on the importance of executive functioning and self-regulation, two mental processes that enable individuals to plan, focus their attention, remember instructions, and multi-task (Harvard University Center on the Developing Child 2018). Growing evidence suggests that 
developing these skills can promote better academic outcomes, altruistic behavior, and social-emotional competence, all of which influence long-term success and well-being (Schonert-Reichl et al. 2015). Individuals are not born with executive functioning and self-regulation skills, but all have the capacity to learn and develop them. Adverse conditions that affect children, particularly in their early years, can severely delay or impair the development of these skills. Therefore, providing the comprehensive care children need in the earliest years of life is crucial, and it is particularly important for children affected by humanitarian crises, as they are at much higher risk of experiencing neglect, trauma, and toxic stress (INEE 2016).

Mindfulness is currently recognized as a valuable component of SEL, as it can enhance executive functioning and self-regulation skills and reduce stress and anxiety (Rocco 2012). While definitions of mindfulness vary, it is commonly understood to be a trait or state of mind that can be developed through a set of practices such as meditation, slow breathing, or intentional movement. Mindfulness also can be developed and practiced through informal everyday activities that use the senses to anchor the attention, such as walking, listening to music, cooking, and eating. By intentionally paying attention to the present in a way that is open, curious, non-reactive, and non-judgmental, individuals can develop the ability to focus on thoughts, feelings, and perceptions that arise from moment to moment (Kaiser Greenland 2010; Stahl and Goldstein 2019).

Although empirical mixed-methods research has been done on the effects of mindfulness in adults, research on the effects of mindfulness in children, specifically in the educational context, has gained momentum only in the last decade (Burke 2009). While some research studies argue that mindfulness has not yet shown any significant effect on child behavior or academic outcomes (Maynard et al. 2017), others suggest that mindfulness may be a promising classroom tool for both teachers and students (Meiklejohn et al. 2012). Recent studies on preprimary and primary school students have shown that using mindfulness practices in the classroom significantly increases social and emotional competence and well-being; it can also improve cognitive skills, working memory, the capacity to plan and organize, classroom behavior, as well as scores on standardized literacy, vocabulary, and mathematics assessments (Schonert-Reichl et al. 2015; Thierry et al. 2015; Razza, Bergen-Cico, and Raymond 2015; Black and Fernando 2014; Kinder 2017). 
There is little available research or documentation specifically on the effects of using mindfulness practices in a humanitarian response. Most available documentation on mindfulness in humanitarian response is on its use with aid workers (Ravelo 2017; Solanki 2015; Byrne 2016), rather than with those directly affected by emergencies. Some initiatives and studies have been conducted or are currently in progress on the use of mindfulness with refugees, such as the Mindfulness-Based Trauma Recovery for Refugees program in Greece and Israel (University of Haifa Observing Minds Lab 2018), the Inhabited Studio program in Hong Kong (Kalmanowitz and Ho 2016), the Mindfulness Without Borders project in the UK (Oxford Mindfulness Center 2016), and mindfulness mental health services offered to refugees and migrants in Australia (Beck 2018; Way Ahead 2016). However, most of these initiatives aim to treat post-traumatic stress among adult refugees residing in countries where they have found final asylum. This gap in research and documentation reinforces the need to test and document mindfulness practices with young learners in humanitarian crises.

\section{LITTLE RIPPLES IN TANZANIA}

\section{The Situation}

In April 2015, Tanzania experienced a major influx of Burundian refugees. As of January 2018, Tanzania was hosting just over 360,000 refugees (76 percent Burundian, and 24 percent Congolese from the Democratic Republic of the Congo, who arrived earlier); of this population, 56 percent were children (UNHCR 2018b). To date, the refugee population continues to be housed in three refugee campsNduta, Mtendeli, and Nyarugusu-in the Kigoma Region of Tanzania; the camps are governed by the Tanzanian Ministry of Home Affairs, coordinated by the United Nations High Commissioner for Refugees (UNHCR), and supported by local and international NGOs.

In the process of being forcibly displaced, many Burundian children and families experienced extreme violence and distress (Human Rights Watch 2017). Through post-arrival interviews and focus group discussions conducted by UNHCR, many refugees reported that family members were murdered, that they had witnessed or experienced physical violence, and/or that they were separated from family members, all of which caused extreme psychosocial distress for individuals of all ages. Moreover, once individuals were assigned to refugee camps in Tanzania, they suffered from extremely poor living conditions and a lack of critical services. Thousands of children arrived in Tanzania as separated and unaccompanied 
minors, which resulted in their being placed in foster care with refugee families that had limited capacity and resources to care for them (Child Protection Working Group, personal communication 2018; Plan International 2016).

While the influx of Burundian refugees into Tanzania slowed significantly in the beginning of 2018, a large school-age population $(145,052)$ existed across the camps ( 23 percent ages 3 to 5, 56 percent ages 6 to 14, and 21 percent ages 15 to 18; UNHCR 2018a). Though there was a structured education system in the camps, a high number of refugee children (44 percent) remained out of school in early 2018 ( 79 percent at the pre-primary level, 22 percent at the primary level, and 97 percent at the secondary level; Education Working Group, personal communication 2018). As there were not enough classrooms to accommodate all learners, many lessons took place outside and were supplemented with non-formal or alternative education support from NGOs, including accelerated learning, early childhood education, technical and vocational training, and adult literacy and numeracy. An interagency assessment conducted at the end of 2017 found that other challenges significantly affected the quality of education offered in the camps at all levels. This included a shortage of teaching and learning materials, lack of access to updated curricula, a lack of qualified teachers, and issues related to exams and recognized certification.

The critical lack of services for the refugees during this period increased the risks they faced, particularly for children ages three to five. The number of childfriendly spaces (CFS) and pre-primary classrooms across the camps could not accommodate all young learners, and many learning spaces were located far from the newer camp zones, making the walking distance too great for young children. Parents and caregivers also put little value on the importance of ECCD, which resulted in low registration and participation rates. Young children who did not participate in early learning programs also often did not receive adequate stimulation or learning support at home, due to their parents' and caregivers' overwhelming domestic responsibilities (e.g., standing in long distribution lines, fetching water or firewood, cooking, doing laundry) and due to the difficulty of adjusting to life in a refugee camp. When these children were kept at home, teachers and social workers were unable to monitor their need for protection or refer them to other support services, such as health and nutrition services, case management, and psychosocial support. Many Burundian refugee children were at risk of falling through the cracks. 


\section{The Partnership}

In mid-2017, Plan International Tanzania (PLAN) began delivering an ECCD program for Burundian refugee children ages three to five in the Nduta and Mtendeli camps. ${ }^{2}$ The goals of this program were to provide safe and inclusive spaces in which young refugee children could learn and grow, and to prepare them to enter and thrive in Grade 1 of the Burundian formal school system. However, in late 2017, attendance and participation in PLAN's ECCD program was steadily decreasing. Program staff members attributed this decrease to a lack of training and professional development for ECCD teachers, few community outreach activities to recruit students, and a lack of knowledge among parents and the wider community about the importance and impact of ECCD.

In early 2018, observing the high number of young refugee children in need of services and the steady rise of risks to children in the camps (e.g., child labor, sexual exploitation and abuse, child trafficking; Child Protection Working Group, personal communication 2018), the PLAN education team decided that they needed a new approach to increase attendance and participation in its ECCD program. Having identified the Little Ripples approach as a contextually relevant and useful model that could help strengthen the quality of its ECCD program, PLAN reached out to iACT to propose bringing Little Ripples to Tanzania. PLAN dedicated funding to support the rollout of a Little Ripples teacher training and to implement the program in Tanzania, while iACT provided trainers, training content, and program materials. ${ }^{3}$

\section{IMPLEMENTATION}

In April 2018, iACT sent two trainers to Tanzania to deliver a Little Ripples teacher training to 40 Burundian refugee ECCD teachers in the Nduta and Mtendeli refugee camps. PLAN selected which teachers would be trained, arranged the logistics, and coordinated the training activities. The goals of the training were to prepare these teachers to deliver the Little Ripples curriculum, improve their teaching skills and the learning environment, and enhance the academic, social, and emotional learning experience for young refugee children in the camps.

\footnotetext{
2 Both Congolese and Burundian refugees were housed in the Nyarugusu refugee camp, but only Burundian refugees were housed in the Nduta and Mtendeli refugee camps. As PLAN was only working in the Nduta and Mtendeli refugee camps at the time it was implementing its ECCD program, the program only reached Burundian refugee teachers and children.

3 While iACT supplied physical trainers, training content, and program materials, PLAN covered all associated costs for these services and materials.
} 
While PLAN required all of its ECCD teachers to have at least a secondary school education, most of the teachers who participated in the Little Ripples training had no official teacher certification and only very limited teaching experience, and they had received little or no training since arriving in Tanzania. ${ }^{4}$ The training, which lasted for one week in each camp, covered child development, classroom organization, play-based learning, positive behavior management, emotional literacy (i.e., the ability to understand and express feelings and empathize with others), and how to create a daily routine. The trainers used a participatory method that provided numerous examples of pedagogical techniques (e.g., verbal, written, and role-play) and gave the participants ample time to practice the techniques discussed and modeled.

The training also incorporated practical mindfulness exercises, such as deep breathing, body scanning, thinking of happy things, and active listening. Teachers were encouraged to use these exercises with their students as fun stand-alone activities, for classroom management, as transition exercises between main classroom activities - and to manage their own stress. ${ }^{5}$ The trainers also discussed the unique needs of young learners affected by displacement and how mindfulness and other techniques could help them build coping mechanisms.

iACT provided boxes of teaching and learning materials for each CFS, including alphabet blocks, building blocks, animal counters, foam puzzle mat pieces, balls, and Kirundi-language picture books and story books. These items were meant to stay in the classroom and be used only for the Little Ripples program. iACT collaborated with the teachers about how to use the items for both free and guided play. Teachers were encouraged to keep inventory of the items to ensure that they did not get lost, broken, or taken, and they were instructed to clean and maintain the materials regularly. The materials introduced basic literacy and numeracy, and teachers were encouraged to think about how they could use the materials to encourage mindfulness, helping, sharing, and peace within the classroom.

Following the teacher training, PLAN conducted a large ECCD registration campaign, coupled with efforts to raise community awareness about the importance of education and early learning. This was done using a public announcement system and by holding town hall meetings with parents and community members.

$4 \quad$ Teacher education levels were recorded and tracked by PLAN internally and response-wide by UNHCR and implementing partners.

5 Parents of Little Ripples students were informed of this training and of the Little Ripples program, but they were not participants in the training or trained in mindfulness. 
From May to June 2018, average monthly attendance in PLAN's ECCD activities increased by 42 percent, from 4,825 individuals to 6,841 . $^{6}$

In the Nduta and Mtendeli refugee camps, Burundian refugee children ages three to five participated in PLAN's CFS from $8 \mathrm{Am}$ to $11 \mathrm{AM}$. Each day began the same way: after greeting children and taking attendance, the ECCD teachers and students formed a circle and the teachers led a mindfulness activity. This routine was intended to build the group's sense of community and set a calm and reflective tone for the day. Teachers then delivered lessons that used academic content from the Burundian pre-primary curriculum that included a variety of engaging activities, including free and guided play, storytelling, games, and songs. These activities incorporated the principles of peace, helping, sharing, hygiene, and emotional literacy, thus encouraging teachers to integrate hand-washing into the daily routine, provide positive verbal feedback when they observed children sharing toys, ask students how they were feeling throughout the day, and use mindfulness activities to help refocus the class and create a peaceful learning environment. Each lesson ended with classroom clean-up, a mindfulness activity, and a goodbye song. After the day's lessons, children returned home for lunch and rest. Some children returned to a CFS in the afternoon for recreational and psychosocial support activities. PLAN also ran a mobile CFS for children living in outer camp zones that were far from the permanent CFS. ECCD teachers and child protection staff members travelled to the different camp zones once a week to deliver ECCD and recreational activities to children.

In addition to planning and delivering lessons, teachers were responsible for conducting community outreach and engaging parents. They regularly encouraged parents to support their children's participation in the program, conducted home visits, and offered strategies to help parents foster their children's physical, cognitive, social, and emotional development at home (e.g., reading with them, ensuring proper hygiene, not using corporal punishment, asking children about their feelings). Teachers and parents interacted through CFS oversight committees (similar to a parent-teacher association), and parents served as volunteers to support the program, such as by monitoring outside play, conducting community outreach, supporting the registration and enrollment process, walking groups of children to and from the CFS, and helping with CFS maintenance.

$6 \quad$ Percentage increase was calculated using the difference between increased average attendance and original average attendance, divided by the original average attendance figures reported in PLAN's May 2018 and June 2018 internal monthly monitoring reports. 


\section{Challenges}

While PLAN's ECCD activities were running relatively well in eight different CFS across the Nduta and Mtendeli refugee camps at the time this paper was drafted (2018-2019), they also faced implementation challenges. One example was food security and nutrition. While the Little Ripples approach in other contexts includes providing meals or nutrition support for students, all education actors working in the Burundian refugee response in Tanzania agreed that no agency would provide food through its education programming unless all agencies could do so equitably and sustainably, to avoid causing an imbalance in the delivery of services or turning learning spaces into potential targets of violence due to general food insecurity in the camps. As a result, children were often hungry by mid-morning, which resulted in ECCD activities being run for only three to four hours, Monday through Friday.

Another challenge was the lack of teachers and classrooms. After the Little Ripples teacher training, which raised community awareness and resulted in robust student enrollment, teacher-student ratios fluctuated between 1:20 and 1:125, depending on the CFS and the students' ages and class levels. To address this, more ECCD teachers were hired to keep up with the increase in registered children and reduce teacher-student ratios. After new teachers were recruited, teacher-student ratios decreased slightly, to between 1:20 and 1:80. ${ }^{7}$ However, the ratios remained higher than desired and classroom space was significantly limited. ${ }^{8}$ To reduce crowding and provide adequate space for quality learning and physical activities, PLAN education staff members worked with ECCD teachers to split the students by age group and rotated different ECCD activities that took place in the shaded areas just outside the classrooms.

Finally, the work conditions and incentives for ECCD teachers also posed a large challenge. While efforts were made to ensure that the CFS were clean, colorful, inclusive, and safe, teachers had few resources available to plan and deliver their lessons; even basic scholastic materials such as notebooks, pens, pencils, etc., were difficult to provide. ${ }^{9}$ Furthermore, teachers were paid according to an interagency

7 In comparison, the required teacher-student ratio in Tanzania is 1:40 (Letea 2018)

8 At the time this article was drafted, the Tanzanian government had put into effect a policy stipulating that no further structures could be built in the camps unless they were permanent structures, which were costly and time-consuming to build.

9 For example, no electricity flowed to the CFS, and computers and tablets were not provided due to limited funds. Teachers also regularly requested items such as bags to carry their lesson plans and teaching materials, branded t-shirts or other clothing to wear while teaching, solar lamps so they could work at night, bicycles to travel to and from the CFS, phones to better communicate with each other, and rainboots and umbrellas to help them get to and from the CFS during the rainy season. 
compensation scale, which resulted in ECCD teachers being paid approximately US $\$ 21$ per month-hardly an adequate living wage in any context..$^{10}$ To address some of these issues, PLAN intended to procure more teaching and learning materials and to increase teachers' monthly stipends.

\section{Assessment Methodology}

Implementation of the Little Ripples program in Tanzania was not originally intended to generate significant research data. However, due to the positive feedback about the program from parents, students, teachers, and other NGOs, combined with the rollout of a new interagency pre-primary academic student assessment, the PLAN education team decided to collect data to document the progress and the perceived effects of the program, and the innovative use of mindfulness. In September 2018, five months after the initial teacher training, PLAN conducted an assessment of the Little Ripples program. The timing of this assessment was due not only to the timing of the new academic student assessment a few weeks prior but to PLAN wanting to take advantage of full staff capacity to conduct the assessment before an impending period of staff turnover.

PLAN staff conducted the assessment using survey questionnaires and focus group discussions (FGD) with teachers, parents, and students. The questionnaires were developed by the PLAN education staff and the monitoring, evaluation, accountability, and learning (MEAL) staff. The questionnaires for parents and teachers were comprised of ten "yes or no" questions, while the parent and teacher FGD allowed participants to provide more in-depth answers to the same questions. Students who participated in FGD were given five questions based on contextually appropriate child-development assessments provided by PLAN's child psychologist. ${ }^{11}$ While there was some uncertainty about the possibility of obtaining meaningful qualitative data from very young children, PLAN's child psychologist, who had had success with this approach on another project, provided support and recommendations for this assessment, which enabled PLAN to obtain feedback from Little Ripples students.

10 In comparison, primary school teachers of community-based schools in Afghanistan earn approximately US\$140 per month (Molina et al. 2018).

11 A more rigorous and established social-emotional assessment tool, such as the Ages and Stages Questionnaires, was not used, as the aim of the assessment was not to measure the individual social-emotional development of each student but to gauge teacher, parent, and student perceptions of student improvement and overall attitudes toward the Little Ripples program, and specifically toward its use of mindfulness. 
All surveys and FGD were administered or supervised by PLAN's education and MEAL staff members, who had been oriented to the questionnaires, FGD questions, and methodology by PLAN's education in emergencies specialist and MEAL advisor. All individuals who collected the assessment data and facilitated FGD had participated in previous education program assessments and had experience in data collection and FGD facilitation. While all survey questionnaires were written in English, they were orally translated into Kiswahili and Kirundi by data collectors in the field; all FGD were conducted in Kiswahili and Kirundi.

Upon completing their work, the data collectors entered all the data from student, teacher, and parent surveys, as well as detailed notes from the FGD, on an Excel spreadsheet; these data were then validated and verified by PLAN's MEAL team. The teacher and parent survey data were recorded using clear "yes or no" indicators. The method of grounded coding for all FGDs was used to extract main themes from the detailed notes taken by the facilitators. Once the main themes were extracted, they were reviewed and validated by all FGD facilitators and by members of the MEAL team to ensure accuracy and integrity. The data analysis and drafting of findings were completed by PLAN's education in emergencies specialist and shared with the education, MEAL, and senior management teams for final review and validation.

\section{Assessment Results}

\section{Student Perspectives}

PLAN's ECCD teachers conducted student FGD, with supervision and guidance from PLAN's education officers and child psychologist. Approximately 70 fiveyear-old children from the two camps participated. When asked to raise their hands if they enjoyed coming to ECCD lessons, most children did so; many children reported that they enjoyed singing, playing games, learning new things, and making friends with other students. Students also reported feeling safe in CFS and ECCD lessons. They said that the teachers were friendly, so they were not worried about being beaten or hurt while there. Most of the students reported that they felt relaxed during lessons and that interacting with other students made them feel happy. When asked what they were learning in their ECCD lessons, the students were able to recall the lesson content (e.g., the alphabet, numbers counting, body parts, animals, colors, shapes, etc.); some were even able to demonstrate a mindfulness meditation exercise. The information reported by the children in these FGD is an interpretation that was translated by the PLAN 
ECCD teachers, education officers, and child psychologist. To ensure that the children understood, the FGD facilitators rephrased questions as needed and asked students to clarify answers that were confusing or if they were not sure the students fully understood the question in the first place.

\section{Teacher Perspectives}

While all of PLAN's 40 ECCD teachers participated in the Little Ripples teacher training, only 36 were still in the camps at the time of the assessment, due to voluntary repatriation. ${ }^{12}$ All remaining teachers completed a survey questionnaire, and 33 teachers ( 55 percent male, 45 percent female) participated in FGD.

Since the training, the vast majority of teachers surveyed (93 percent) were incorporating mindfulness exercises they learned during the teacher training into their teaching practice. In FGD, teachers acknowledged the psychosocial value of mindfulness, mentioning that it makes students feel more comfortable and fosters a safe, enjoyable learning environment. Teachers also saw the value of mindfulness in behavior management; they felt more connected to their students' moods and feelings and could use mindfulness exercises to refocus children when needed. Teachers reported that the most effective exercises with their students were those that did not require too much narration, such as focused breathing, while exercises such as body scans were more difficult to use, due to students' limited language and vocabulary skills. Teachers reported in the FGD that the training increased their understanding of teaching methodologies and strengthened their behavior management skills, and that the training increased their confidence, which enabled them to bring more energy and enthusiasm to their students.

All teachers surveyed reported having seen an improvement in their students' academic performance and behavior. While they did not give uniformly positive responses, teachers participating in the FGD generally felt that the improved academic performance was due to students' increased confidence, their ability to focus better on lessons, and greater participation. Teachers also noticed a more peaceful and cooperative feel to their classrooms, reported fewer student conflicts, and saw an improvement in student hygiene. All reported improvements were based on teachers' personal observations of their students and their ongoing assessments, rather than on a formal comparison of baseline and endline summative assessment data.

12 More teachers have been hired since this time. 
Fewer than half of the teachers surveyed (39 percent) reported using mindfulness techniques for themselves. This was attributed to their busy schedules and to their desire to have someone talk them through a mindfulness exercise, which suggests their interest in incorporating these practices into their personal lives if they could receive further guidance.

\section{Parent Perspectives}

To understand the perceived effects of the Little Ripples program on children outside of the classroom, a group of parents of ECCD students was selected at random and asked to complete a questionnaire and participate in FGD. A total of 38 parents ( 47 percent male, 53 percent female) participated. ${ }^{13}$

The majority of parents surveyed ( 85 percent) reported that their children who participated in ECCD had experienced some form of extreme distress or hardship. ${ }^{14}$ Most (72 percent) saw this as having a negative impact on their children, including poor academic performance and a decline in their physical and mental health and well-being. Parents reported that their children had witnessed or experienced violence, and some had witnessed the death of a parent or other family member. Parents also mentioned that many ECCD students lived in either single-parent households or in situations where domestic violence was common. Many parents also reported that, before participating in ECCD, their children had seemed sad or stressed, appeared lonely, had trouble sleeping, found it difficult to make friends, and would cry for no particular reason. Parents also highlighted the adverse influence violence and displacement had on their own stress levels.

The vast majority of parents surveyed reported seeing an improvement in their children's behavior ( 98 percent) and learning ( 93 percent) since participating in ECCD; most parents (95 percent) attributed these improvements to the ECCD lessons. In FGD, many parents reported that their children were now more talkative and energetic, more comfortable with other children and adults, had happier dispositions, and displayed positive attitudes. Parents also reported that their children sang songs they learned in ECCD lessons and that their children were now able to count, say the alphabet, and greet others appropriately. All improvements reported were based on parents' personal observations and their perceptions of their children.

13 The low participation of parents is due to busy schedules related to standing in long distribution lines and doing domestic chores.

14 Many parents had multiple children participating in ECCD at the same time. 
Almost all the parents surveyed (98 percent) were familiar with the mindfulness techniques the ECCD teachers were using, and most (86 percent) felt that these techniques were helping their children deal with stress and enabled them to learn better. Most parents (87 percent) said they saw their children using mindfulness techniques at home or elsewhere outside the classroom. In the FGD, parents credited the mindfulness techniques with improving their children's ability to listen, concentrate, and stay calm in ECCD lessons and at home. Some parents (43 percent) reported that they were considering using mindfulness exercises themselves.

\section{CONCLUSION}

Young Burundian refugee children in Tanzania who have been affected by violence and displacement continue to face numerous risks and challenges that could negatively affect them well into adulthood. However, some of these negative effects can be mitigated by participating in safe, inclusive, and engaging learning and recreational activities. ECCD programming can help restore these children's sense of safety, routine, and comfort in an otherwise chaotic and unpredictable environment. Participating in ECCD enables these children to exercise their right to receive an education that provides the stimulation and support they need for healthy growth and development.

The ECCD programming provided in the Nduta and Mtendeli refugee camps in Tanzania has yielded perceived positive changes in student learning outcomes and behavioral development. Burundian refugee teachers and parents alike have reported seeing positive changes in ECCD students, both during and outside their ECCD lessons, including better retention of academic content, happier dispositions, and increased confidence and comfort when participating in lessons and interacting with others. While we are unable to definitively demonstrate that this initiative established a clear route for the participating refugee children to enter Grade 1 of the Tanzanian formal school system, their parents report that they increasingly value education and early learning for their children, which is a promising indicator.

Based on teacher and parent reports, the Little Ripples approach, including the specific focus on social-emotional learning through mindfulness, may be a significant factor in strengthening PLAN's ECCD program in Tanzania. While it is difficult to establish a direct correlation between the use of mindfulness in the classroom and the positive changes perceived in ECCD students' academic 
performance and social-emotional well-being, it can be posited that the incorporation of mindfulness has enhanced the students' overall ECCD experience. The fact that students report enjoying mindfulness exercises, that parents see their children doing mindfulness exercises at home, and that teachers report that students respond positively to mindfulness exercises during their ECCD lessons supports the inference that children are consciously or unconsciously gaining mindfulness skills that they will be able to rely on as they grow.

As previous low participation and attendance in ECCD was attributed to refugee parents' negative attitudes, it is vital to note the positive changes in their attitudes toward early learning. Many refugee parents report seeing positive changes in their children since the Little Ripples approach was introduced; they attribute these changes to their children's participation in ECCD and to their learning to manage stress through mindfulness. Parent-teacher relationships and parental involvement in ECCD appear to have been strengthened through community outreach, and both will likely have a positive influence on student learning, emotional wellbeing, and resilience going forward (Graham, Minhas, and Paxton 2016; Park and McHugh 2014).

It is important to acknowledge the perceived positive results from the use of mindfulness as a teaching tool. Based on feedback from ECCD teachers, mindfulness has proven to be an effective instrument for managing student behavior and in creating a more positive and peaceful learning environment. Teachers reported feeling more confident and happier in their work after receiving teacher training and said they were able to manage their students more effectively-a factor in improving the quality of teaching and learning (Jennings 2015; Flook et al. 2013). However, few teachers report using mindfulness to manage their own stress, which is a subject to explore going forward.

Finally, given that humanitarian funding for the education sector remains critically low, it will be important to further examine the incorporation of mindfulness in ECCD in emergencies as a low-cost and easily replicable intervention. ${ }^{15}$ With some basic training, teachers can easily integrate mindfulness into learning spaces and deliver it to a large group of children without the need for physical materials. My hope is that this case study will provide critical evidence on the perceived positive effects mindfulness can have on young learners and teachers affected by humanitarian crises and encourage more practitioners to integrate, test, and document the use of mindfulness with young learners in emergency contexts.

15 In 2017, the education sector received only 3.8 percent of all humanitarian funding, an increase from 1.7 percent in 2014 . 


\section{ACKNOWLEDGMENTS}

I would like to acknowledge the extremely hard work of the Burundian refugee teachers and the PLAN education team members who deliver and manage the Little Ripples program in Tanzania. I would also like to acknowledge the work done by the PLAN education officers to conduct the assessment that generated the data presented above, as well as the PLAN MEAL team for providing support and guidance on designing and conducting the assessment. I would like to thank Sara-Christine Dallain for her support and contributions to this paper, and Sweta Shah and the INEE editorial team for their support in enhancing its quality and clarity. Finally, I would like to thank the Norwegian Agency for Development Cooperation, which funds the Little Ripples program in Tanzania, for making the program possible.

\section{REFERENCES}

Beck, Collette. 2018. "Mindfulness Is Helping Refugees and Migrants Deal with Trauma." Special Broadcasting Service. https:/www.sbs.com.au/topics/life/ health/article/2018/06/21/mindfulness-helping-refugees-and-migrants-dealtrauma.

Black, David, and Randima Fernando. 2014. "Mindfulness Training and Classroom Behavior Among Lower-Income and Ethnic Minority Elementary School Children." Journal of Child and Family Studies 23 (7): 1242-46. http://doi. org/10.1007/s10826-013-9784-4.

Black, Maureen M., Susan P. Walker, Lia C. H. Fernald, Christopher T. Andersen, Ann M. DiGirolamo, Chunling Lu, Dana C. McCoy et al. 2018. "Early Childhood Development Coming of Age: Science through the Life Course." The Lancet 389 (10,064): 77-90. https://doi.org/10.1016/S0140-6736(16)31389-7.

Bouchane, Kolleen, Molly Curtiss, and Bethany Ellis. 2016. Safe Spaces: The Urgent Need for Early Childhood Development in Emergencies and Disasters. London: Theirworld. 
Bouchane, Kolleen, Hirokazu Yoshikawa, Katie Maeve Murphy, and Joan Lombardi. 2018. "Early Childhood Development and Early Learning for Children in Crisis and Conflict." Paper commissioned for the 2019 GEM Report: Migration, Displacement and Education. Building Bridges, Not Walls. Paris: UNESCO. https://unesdoc.unesco.org/ark:/48223/pf0000266072.

Burke, Christine. 2010. "Mindfulness-Based Approaches with Children and Adolescents: A Preliminary Review of Current Research in an Emergent Field." Journal of Child and Family Studies 19 (2): 133-44. https://doi. org/10.1007/s10826-009-9282-x.

Byrd, Hannah Taylor. 2019. "Using Social-Emotional Learning to Help Behavioral Problems." Capstone Projects and Master's Theses 438. https://digitalcommons. csumb.edu/caps_thes_all/438.

Byrne, Hugh. 2016. "Mindfulness Training for Syrian Refugee Aid Workers." Mindful Magazine, December 14, 2016. https://www.mindful.org/mindfulnesstraining-syrian-refugee-aid-workers/.

CASEL. 2018. "Core SEL Competencies." https://casel.org/core-competencies/.

Flook, Lisa, Simon B. Goldberg, Laura Pinger, Katherine Bonus, and Richard J. Davidson. 2013. "Mindfulness for Teachers: A Pilot Study to Assess Effects on Stress, Burnout, and Teaching Efficacy." Mind, Brain and Education 7 (3): 182-95. https://doi.org/10.1111/mbe.12026.

Foundation for a Mindful Society. 2017. "Jon Kabat-Zinn: Defining Mindfulness." Mindful Magazine, January 11, 2017. https://www.mindful.org/jon-kabatzinn-defining-mindfulness/.

Gertler, Paul, James Heckman, Rodrigo Pinto, Arianna Zanolini, Chirstel Vermeersch, Susan Walker, Susan M. Chang, and Sally Grantham-McGregor. "Labor Market Returns to an Early Childhood Stimulation Intervention in Jamaica." Science 344 (6,187): 998-1,001. https://doi.org/10.1126/ science.1251178.

Graham, Hamish R., Ripudaman S. Minhas, and Georgia Paxton. 2016. "Learning Problems in Children of Refugee Background: A Systematic Review." Pediatrics 137 (6): 1-15. https://doi.org/10.1542/peds.2015-3994. 
Harvard University Center on the Developing Child. 2018. "Executive Function and Self-Regulation." https://developingchild.harvard.edu/science/keyconcepts/executive-function/.

Human Rights Watch. 2017. "Burundi: Events 2017." https://www.hrw.org/worldreport/2018/country-chapters/burundi.

Inter-agency Network for Education in Emergencies (INEE). 2016. INEE Background Paper on Psychosocial Support and Social Emotional Learning for Children and Youth in Emergency Settings. New York: INEE.

Inter-agency Network for Education in Emergencies (INEE). 2017. "Early Childhood Development." https://inee.org/collections/early-childhooddevelopment.

Jennings, Patricia. 2015. “Early Childhood Teachers' Well-Being, Mindfulness, and Self-Compassion in Relation to Classroom Quality and Attitudes Towards Challenging Students." Mindfulness 6 (4): 732-43. https://doi.org/10.1007/ s12671-014-0312-4.

Jones, Stephanie M., and Suzanne M. Bouffard. 2012. "Social and Emotional Learning in Schools: From Programs to Strategies and Commentaries." Social Policy Report 26 (4): 1-33. https://doi.org/10.1002/j.2379-3988.2012.tb00073.x.

Kabat-Zinn, Jon. 2003. "Mindfulness-Based Stress Reduction (MBSR)." Constructivism in the Human Sciences 8 (2): 73-83.

Kaiser Greenland, Susan. 2010. The Mindful Child: How to Help Your Kids Manage Stress and Become Happier, Kinder, and More Compassionate. New York: Simon and Schuster.

Kalmanowitz, Debra, and Rainbow Tin Hung Ho. 2016. "Out of Our Mind. Art Therapy and Mindfulness with Refugees, Political Violence and Trauma." The Arts in Psychotherapy 49: 57-65. https://doi.org/10.1016/j.aip.2016.05.012.

Kinder, Michelle. 2017. "Why Mindfulness Belongs in the Classroom." Mindful Magazine, January 25, 2017. https://www.mindful.org/why-mindfulnessbelongs-in-the-classroom/. 
Letea, Halili. 2018. "Teacher-Student Ratio Still a Concern.” The Citizen. https:// www.thecitizen.co.tz/news/1840340-4562922-5wab5gz/index.html.

Maynard, Brandy R., Michael R. Solis, Veronica L. Miller, and Kristen E. Brendel. 2017. "Mindfulness-Based Interventions for Improving Cognition, Academic Achievement, Behavior, and Socioemotional Functioning of Primary and Secondary School Students." Campbell Systematic Reviews 5: 1-147. https:// doi.org/10.4073/CSR.2017.5.

Meiklejohn, John, Catherine Phillips, M. Lee Freedman, Mary Lee Griffin, Gina Biegel, Andy Roach, Jenny Frank, et al. 2012. "Integrating Mindfulness Training into K-12 Education: Fostering the Resilience of Teachers and Students.” Mindfulness 3 (4): 291-307. https://doi.org/10.1007/s12671-0120094-5.

Molina, Ezequiel, Iva Trako, Anahita Hosseini Matin, Eema Masood, and Mariana Viollaz. 2018. The Learning Crisis in Afghanistan. Washington, DC: World Bank. http://documents.worldbank.org/curated/en/588881536147087211/ AUS0000428-REVISED-SABER-SD-Afghanistan-digital-9-27.pdf.

Oxford Mindfulness Center. 2016. "Mindfulness Without Borders: Refugees.” http:// oxfordmindfulness.org/about-us/about/charitable-activities/accessibilityfund-2016/mindfulness-without-borders-refugees/.

Park, Maki, and Margie McHugh. 2014. Immigrant Parents and Early Childhood Programs: Addressing Barriers of Literacy, Culture, and Systems Knowledge. Washington, DC: Migration Policy Institute.

Plan International. 2013. Early Childhood Care and Development in Emergencies: A Programme Guide. Woking, UK: Plan International.

Plan International. 2016. "Safety for Burundian Children in Tanzania." https:// plan-international.org/safety-burundian-refugee-children-tanzania.

Ravelo, Jenny Lei. 2017. "Mindfulness Meditation: Can This Practice Help Mitigate Aid Worker Stress?” Devex News. https://www.devex.com/news/mindfulnessmeditation-can-this-practice-help-mitigate-aid-worker-stress-89997. 
Razza, Rachel, Dessa Bergen-Cico, and Kimberly Raymond. 2015. "Enhancing Preschoolers' Self-Regulation via Mindful Yoga." Journal of Child and Family Studies 24 (2): 372-85. https://doi.org/10.1007/s10826-013-9847-6.

Rocco, Sharn. 2012. "Mindfulness for Well-Being in Schools: A Brief Survey of the Field." Redress 21 (3): 14.

Schonert-Reichl, Kimberly A., Eva Oberle, Molly Stewart Lawlor, David Abbott, Kimberly Thomson, Tim F. Oberlander, and Adele Diamond. 2015. "Enhancing Cognitive and Social-Emotional Development through a Simpleto-Administer Mindfulness-Based School Program for Elementary School Children: A Randomized Controlled Trial." Developmental Psychology 51 (1): 52-66. http://doi.org/10.1037/a0038454.

Solanki, Hitendra K. 2015. Mindfulness and Well-Being Mental Health and Humanitarian Aid Workers: A Shift of Emphasis from Treatment to Prevention. Geneva: CHS Alliance.

Stahl, Bob, and Elisha Goldstein. 2019. A Mindfulness-Based Stress Reduction Workbook. Oakland, CA: New Harbinger Publications.

Thierry, Karen L., Heather L. Bryant, Sandra Speegle Nobles, and Karen S. Norris. 2016. "Two-Year Impact of a Mindfulness-Based Program on Preschoolers' Self-Regulation and Academic Performance." Early Education and Development 27 (6): 805-21. https://doi.org/10.1080/10409289.2016.1141 616.

UNHCR. 2018a. "Population of School Age Refugees." Geneva: UNHCR.

UNHCR. 2018b. “Tanzania Refugee Situation Statistical Report-2018.” Geneva: UNHCR. https://data2.unhcr.org/en/situations/burundi/location/2034.

UNICEF. 2012. Noteworthy Practices: Early Childhood Development in Emergencies. New York: UNICEF. https://inee.org/system/files/resources/ UNICEF_NoteworthyPractices_2013_En.pdf.

University of Haifa Observing Minds Lab. 2018. "Current and Future Research." https://irca-haifa-6h5e.squarespace.com/irca\#item=our-mission. 
Way Ahead. 2016. "Arabic Mindfulness.” https://wayahead.org.au/arabicmindfulness/.

Weissberg, Roger P. 2019. "Promoting the Social and Emotional Learning of Millions of School Children.” Perspectives on Psychological Science 14 (1): 65-9. https://doi.org/10.1177/1745691618817756.

World Bank Group, United Nations Children's Fund, and Inter-American Development Bank. 2018. G20 Development Working Group: Investing in Early Childhood Development. Washington, DC: World Bank Group. https://www. ecdan.org/assets/background-study---early-childhood-development.pdf.

World Health Organization, United Nations Children's Fund, and World Bank Group. 2018. Nurturing Care for Early Childhood Development: A Framework for Helping Children Survive and Thrive to Transform Health and Human Potential. Geneva: World Health Organization. https://apps.who.int/iris/ bitstream/handle/10665/272603/9789241514064-eng.pdf.

Zins, Joseph E., and Maurice J. Elias. 2006. "Social and Emotional Learning: Promoting the Development of All Students." Journal of Educational and Psychological Consultation 17 (2-3): 233-55. https://doi. org/10.1080/10474410701413152. 